\title{
Atores e discursos em Projetos de Autogestão da Moradia em São Paulo
}

\author{
Agentes y discursos en proyectos de la autogestión de la cubierta en São Paulo
}

Actors and speeches in Projects of housing self-management in São Paulo

\author{
Priscilla Oliveira Xavier
}

Palavras chave:

Produção do espaço

Etnografia

Autogestão

\section{Resumo:}

A presente investigação pretende analisar manifestações e discursos de agentes envolvidos na produção e usos da cidade em projetos voltados para a construção de habitações por autogestão. Toma-se como evento uma visita a projetos em andamento na cidade de São Paulo. São privilegiadas para análise ações e discursos de moradores, lideranças articuladoras e assessoria técnica. Parte-se da perspectiva de que tais ações e discursos são elementos profícuos para compreensão da questão da habitação autogestionada, seja pela relação entre Estado e a sociedade civil, seja pela relação entre demandantes por moradias e demais articuladores. Apreende-se dessas relações os elementos que potencialmente conferem coesão e/ou distinção entre os grupos, a partir da hipótese de que a natureza das relações se reflete no padrão das habitações, na administração dos conjuntos habitacionais, na sociabilidade da vizinhança e no desenvolvimento do entorno. 


\section{Resumen:}

La actual investigación se prepone analizar manifestaciones y discursos de agentes implicados en la producción y las aplicaciones de la ciudad en los proyectos dirigidos hacia la construcción de los habitations para la autogestión. Una visita se supera como acontecimiento los proyectos en marcha en la ciudad de São Paulo. Son privilegiados para la acción del análisis y los discursos de habitantes, de los articuladores y de la assessoria técnica. Eso ha estado quebrado de la perspectiva de tales acciones y los discursos son elementos de los profícuos para la comprensión de la cuestión del habitation autogestionada, cualquiera para la relación entre el estado y la sociedad civil, cualquiera para la relación entre el demandante para las cubiertas y demasiado los articuladores. Uno prende de estas relaciones los elementos que potencialmente confieren cohesión y/o distinción entre los grupos, de la hipótesis de eso la naturaleza de las relaciones si refleja en el estándar de los habitations, en la administración de los sistemas de los habitacionais, en el sociability de la vecindad y el desarrollo del entorno.

\section{Palabras clave:}

Producción del espacio

\section{Etnografia}

Autogestión

\section{Key words:}

Production of the space

\section{Ethnography}

Self-management

\section{Abstract:}

The present inquiry intends to analyze manifestations and speeches of involved agents in the production and uses of the city in projects directed toward the construction of habitations for self management. A visit is overcome as event the projects in progress in the city of São Paulo. They are privileged for analysis action and speeches of inhabitants, leaderships and technical questions. That has been broken of the perspective of such actions and speeches is hard elements for understanding of the question of the self-management habitation, either for the relation between State and the civil society, either for the relation between plaintiff for housings and too much agents. One apprehends of these relations the elements that potentially confer cohesion and/or distinction between the groups, from the hypothesis of that the nature of the relations if reflects in the standard of the habitations, in the administration of the housing sets, in the sociability of the neighborhood and the development of the place. 


\section{Atores e discursos em Projetos de Autogestão da Moradia em São Paulo}

\section{INTRODUÇÃO}

O presente artigo tem como base a concepção da etnografia como uma construção discursiva que objetiva destacar e abordar referencialmente aspectos sócio-culturais e políticos de agentes sociais atuantes na questão da construção habitacional por autogestão coletiva. Peirano (2001) serve de instrumental teórico para tratar eventos como acontecimentos capazes de instituir fronteiras sociais, consagrar e disseminar símbolos e significados. A abordagem inspira-se ainda no trabalho de Goffman (1975) que apresenta um enfoque dramatúrgico das interações sociais, investindo nos diversos mecanismos de construção social da imagem acionados pelos indivíduos em contextos públicos, em decorrência de seu pertencimento institucional.

\section{A VISITA}

No dia 12 de Dezembro de 2010, um grupo de alunos da UFRJ e de representantes da Fundação Bento Rubião partiu do centro do Rio de Janeiro rumo a São Paulo. O objetivo da viagem era um encontro com lideranças da União dos Movimentos de Moradia para conhecer experiências urbanas de produção habitacional por autogestão coletiva na cidade de São Paulo.

A primeira parada em São Paulo foi na sede de um dos Movimentos por Moradia. Era uma casa de dois andares, onde na parte térrea era possível ver cerca de trinta pessoas se acomodando a espera de uma reunião. Partindo da sede Donizete, coordenador de São Paulo da União
Nacional por Moradia Popular, conduziu o grupo para o conjunto Colinas do Oeste, ainda em fase de obras, situado no bairro Jaraguá, Zona Norte da Capital.

No dia 13 de Dezembro o grupo passou a ser guiado por Edilson, também membro do Movimento por Moradia. O grupo foi conduzido primeiramente até o Conjunto Paulo Freire, já entregue aos moradores, e na sequência ao conjunto Unidos Venceremos, ainda em fase de obras. Ambos os conjuntos situados em Guaianazes, São Miguel. Ao final da tarde, por indicação de Edilson mas sem sua presente, o grupo visitou o conjunto Pirineus, que distinto dos demais locais visitados era situado na região central de São Paulo, no bairro Santa Cecília. No dia 14 de Dezembro, sem guia, o grupo conheceu o Conjunto Habitacional Vila Patrimonial, em fase de obras, em Vila Élida, Diadema.

\section{PROJETOS DE AUTOGESTÃO E ASSESSORIA TÉCNICA}

No final dos anos de 1990 a questão da habitação popular ganha uma nova perspectiva. A constituição de 1988 alinhou normatizações que incidiram nas práticas democráticas e participativas. A pouca eficiência das políticas públicas para a habitação até então implantadas somada a crescente complexidade deste problema incidiu na necessidade de criação de programas que fomentassem a questão sócio-habitacional. Dos programas desenvolvidos no período destaca-se uma linha de autogestão, associado ao planejamento urbano e a preservação do meio ambiente.

Os programas habitacionais autogeridos apóiam-se no tripé da dignidade humana, do desenvolvimento sustentável e da redução das desigualdades sociais. 
Sugerem soluções que incidam objetivamente na redução dos custos e agilidade nos processos de auto-empreendimento. Para tal efeito entram em cena as acessorias técnicas que, junto aos sujeitos que demandam habitação, desenvolvem assistência jurídica, social, contábil, de arquitetura e de engenharia.

A assessoria técnica passa a ser um elemento decisivo para o sucesso da política voltada para os projetos de habitação por autogestão. A assessoria é o interlocutor que comprova para o Estado a capacidade das organizações populares de administrar todo o processo produtivo, atendendo aos critérios de viabilidade financeira, qualidade de habitação e eficiência dos projetos urbanísticos.

Embora tratado de modo muito sintético, os parágrafos acima nos ajudam a compreender os pontos básicos da questão que estamos nos enveredando, ou seja, em que contexto surge a política de programas habitacionais autogeridos, quais são os seus princípios norteadores e os agentes nela envolvidos.

\section{DEMANDA/DEMANDANTE}

Se há um erro pelo qual um cientista social se imprime culpa este é o de naturalizar conceitos e categorias. A esquiva de tal falta nesta etnografia está no exercício de desnaturalização de uma categoria cuja presença foi unânime nas falas dos vários agentes no decorrer das visitas. Todos os sujeitos ouvidos proferiam a categoria demanda. Portanto, esta foi a porta de entrada para a análise dos discursos na questão da habitação autogestionada.

Em termos denotativos ${ }^{1}$ a demanda é descrita como procura, busca, desejo, ação judicial, quantidade de mer- cadoria ou serviço que uma coletividade necessita. Do desejo, do jurídico e do econômico a demanda parece se constituir nos discursos dos agentes envolvidos na questão da habitação autogestionada como uma categoria política.

Para fins de políticas o Estado reconhece grupos sociais conforme uma demanda. Tal reconhecimento é hierarquizado pela escala municipal, estadual e, por fim, federal. Para pertencer a uma demanda os indivíduos precisam se enquadrar em alguns critérios, dos quais, para as políticas de habitação de interesse social, podemos citar o de integrar família e estar nas faixas de renda definidas pelo Poder Executivo Federal. Ainda em relação a critérios, têm prioridade famílias residentes em áreas de risco ou insalubres ou que tenham sido desabrigadas, e famílias com mulheres responsáveis pela unidade familiar.

Atendendo critérios, mencionados e demais, e incorporados a um grupo organizado e politicamente atuante os agentes passam a ser qualificados como demandantes, individualmente. E como demanda, coletivamente.

Os demandantes confiam sua demanda, questão/processo, a uma assessoria técnica, cuja atuação é a de um interlocutor entre demandantes e Estado. A atuação primeira da assessoria técnica é a identificação da demanda. Tal identificação abarca questões sociais, políticas, econômicas e culturais. A partir dela é que se desenvolve um projeto que concilie tanto os padrões estabelecidos pelo Estado para habitações de interesse social, quanto as necessidades e desejos dos demandantes.

Analisando a complexidade das práticas e discursos nas questões da habitação cooperativa podemos intuir que 
demanda não é uma categoria utilizada pelo Estado, assessoria técnica e sociedade civil de modo equivalente. No que pese a distinção, o Estado se pauta na demanda genérica, segundo critérios básicos². As assessorias técnicas operam com a demanda genérica padronizada pelo Estado, e com a demanda específica de um grupo organizado que contrata seus serviços. Já a sociedade civil organizada lida com a demanda relativa a um conjunto de critérios do Estado que Ihe confere unidade enquanto grupo em um contexto social, uma legitimidade enquanto organização política atuante e uma peculiaridade enquanto contratador de um serviço.

\section{O SISTEMA DE MUTIRÃO}

Os projetos de construção de moradias por autogestão têm como base a participação dos indivíduos no processo de produção da moradia. A participação não se restringe ao comparecimento em reuniões para decidir aspectos gerais. Estende-se ao investimento da mão-de-obra na construção.

O emprego da mão de obra na construção da habitação é popularmente conhecido como mutirão. Embora o sistema de mutirão seja sempre mencionado como uma experiência envolvente e descontraída, é nas falas sobre o mutirão que algumas questões delicadas emergem.

O sistema de mutirão se sustenta na reversão das horas livres do trabalho regular em horas aplicadas na construção da casa própria. Este trabalho ocorre frequentemente nos finais de semana. $\mathrm{E} o$ grande incentivo para a adesão dos indivíduos ao sistema de mutirão é o cálculo entre valor de hora/trabalho na construção civil e a hora/trabalho dos demandantes. De modo geral ${ }^{3}$, os demandantes gastariam muito mais horas em seus trabalhos regulares para pagar pela mão-de-obra na construção de suas casas.

Cabe destacar que a adesão ao sistema de mutirão não dá conta de todo o trabalho de construção. Ou seja, não anula a contratação de mão-de-obra. E a contratação de mão-de-obra nos projetos autogestionados obedece as mesmas regras vigentes para a contratação de mão-de-obra nos projetos tocados por empresas privadas.

Em todos os projetos de autogestão visitados o mutirão é acompanhado por um esquema de pontuação. O comparecimento, a pontualidade, o compromisso e o tempo de mutirão são computados numa tabela que ranqueia os participantes. A posição no ranque ordena a escolha dos apartamentos.

Se algum dos mutirantes obtiver nas pontuações um número excessivo de faltas o caso é encaminhado para uma assembléia. $\mathrm{Na}$ assembléia é decidido se o elemento faltoso permanece ou não do grupo. E no caso da permanência decidem que sansões o faltoso terá.

Nas visitas feitas aos projetos autogestionados o assunto mutirão invariavelmente suscitava narrativas graciosas. No conjunto Colinas do Oeste, por exemplo, o responsável pela assessoria técnica contou a história de uma senhora que gostava tanto do mutirão que findo o trabalho para construir a própria casa, esta passou a trabalhar no mutirão de um outro projeto, para a construção da casa da neta.

No conjunto Paulo Freire uma das moradoras falou longamente do mutirão. Comentou que nos finais de semana diversas famílias iam parar naquele terreno que as pessoas ao redor nem sabiam do que se tratava. Disse que logo 
foram se apresentar na igreja, explicando que o terreno era deles e que iriam tocar um projeto. Esclareceu para a comunidade que a chegada do mutirão não se tratava de uma invasão ou um de grupo de baderneiros.

Esta mesma moradora do conjunto Paulo Freire disse que no início do mutirão nada havia nas redondezas. E salientou que conforme iam carpindo o terreno, pondo suas obras adiante, o bairro ia se modificando. Deu como exemplo o comércio, que assim que chegaram pouco tinha a oferecer. Os líderes do mutirão iam até o comércio local e solicitavam tais e tais provisões, para um bom número de pessoas, e ao passo que as obras avançavam o comércio se desenvolvia. Quando o conjunto ficou pronto o bairro já contava com uma boa estrutura ao redor. A moradora foi enfática ao dizer que eles são consumidores, que eles compram mesmo.

No Conjunto Unidos Venceremos, ao lado do conjunto Paulo Freire, uma proprietária que trabalhava como zeladora da obra recepcionou o grupo visitante. Em relação ao sistema de mutirão mencionou as distinções das capacidades físicas dos indivíduos, como é o caso de idosos e portadores de necessidades especiais. Ressaltou que as atividades respeitam os limites das pessoas. Por exemplo, os idosos não precisam pegar peso ou levantar uma parede, pois podem ajudar na cozinha, servindo café ou água. Embora considerasse esses serviços mais leves, eram atividades também muito importantes para o andamento das obras.

Seja por critérios físicos, instrução ou demais vocações relativas à psicologia de grupo, a distribuição das atividades no mutirão pode ser tratada como uma oportunidade para o desenvolvimento de talen- tos. O bom desempenho no mutirão confere destaque a alguns elementos que acabam atuando como lideranças. Há nesta observação pendor Darwinista da seleção dos indivíduos mais aptos. Desta feita, do mutirão é que são selecionados os futuros responsáveis pela gestão e manutenção do conjunto habitacional depois de prontos e entregues aos moradores.

Como exemplo do desenvolvimento de potencialidades destaca-se o testemunho da moradora do conjunto Paulo Freire. Em virtude de um bom encaminhamento do grupo no decorrer do mutirão a moradora descobriu sua vocação. O mutirão foi a experiência que a motivou retomar os estudos e ingressar no curso de serviço social. E mesmo finda a obra, com os apartamentos entregue aos moradores, esta moradora continua atuando no auxílio e esclarecimento de questões diversas.

Ainda em relação ao mutirão, nos conjuntos Paulo Freire e Unidos Venceremos houve um destaque à presença majoritária das mulheres. Em ambos os casos houve relatos de mulheres que compareciam assiduamente enquanto seus maridos, ditos enormes e fortes, nunca compareciam para ajudar em nada. No Unidos Venceremos relatou-se o caso de um marido que apareceu apenas no dia da escolha do apartamento. Todavia, as lideranças do grupo colocaram-no de lado, ficando a escolha a cargo exclusivamente da mulher. Já no conjunto Paulo Freire o desfecho relatado da não colaboração do homem foi um pouco mais longo e sofisticado. Disse a moradora que até deixou o marido acompanhar o andamento das obras, para ele ver como o prédio estava ficando bonito. Mas no dia da mudança ele nem precisou se dar ao trabalho de fazer as malas, pois ela se mudou sem ele. Por tais relatos o mutirão nos acrescenta questões instigantes, como um corte de gênero e a emancipação pela consciência política e social. 
No conjunto Vila Patrimonial uma futura moradora nos guiou pela obra. Embora fosse uma segunda-feira, na obra estavam trabalhando alguns mutirantes. Ela mencionou que havia pessoas que não conseguiam comparecer às obras nos finais de semana, e por isso pagavam a quota de trabalho nos dias úteis. Esclareceu que no Conjunto Vila Patrimonial o envolvimento de homens e mulheres era equilibrado, e que até os filhos podiam ajudar, desde que tendo mais de 18 anos. Explicou também que todos os mutirantes que entravam para trabalhar nas obras eram obrigados a fazer um seguro. $E$ o seguro contratado pelos mutirantes do Conjunto Vila Patrimonial era o de um banco privado, visto que o mesmo serviço na Caixa Econômica Federal custava o dobro, segundo a moradora.

O mutirão foi um dos assuntos tratados por Candido (1964) num trabalho que passou da teoria literária e do folclore para uma sociologia dos meios de vida dos caipiras do município de Bofete, em São Paulo. Aborda as formas de solidariedade, enfatizando que na sociedade caipira a sua manifestação mais forte é o mutirão. O mutirão consiste na reunião de vizinhos, convocados por um deles, para efetuar um trabalho determinado, sem uma remuneração direta em espécie. A necessidade de ajuda e a retribuição automática determinavam a formação de uma rede de relações, ligando os habitantes de vizinhanças, contribuindo para sua unidade estrutural e funcional da localidade. $O$ que Candido (1964) descreve são formas bem desenvolvidas de cooperação vicinal, divisão do trabalho, consciência de grupo e coordenação de atividades. Tratava-se de uma ação coletiva numa sociedade onde imperavam traços tradicionais, num contexto de transição para o moderno.

O mutirão em prol da construção da moradia por autogestão se insere num contexto urbano moderno. Entretanto, é também uma forma de cooperação, com resquícios tradicionais. Ou seja, uma relação híbrida na pessoalidade e impessoalidade, na formalidade e informalidade, numa trama de valores morais e distinções culturais.

\section{VIZINHANÇA}

As relações com a vizinhança entram vigorosamente na preocupação dos moradores das habitações autogestinadas, e a relação do projeto com o entorno na preocupação das assessorias técnicas.

No conjunto Paulo Freire uma moradora falava de experiências conturbadas com os moradores de um conjunto ao lado, construído pela $\mathrm{COHAB}^{4}$. Alegava que os vizinhos da COHAB eram pessoas com pouca consciência, nenhuma educação, e que até lixo jogavam no terreno deles. Enquanto os moradores do Paulo Freire se reuniam e zelavam pela construção de qualidade, ordenamento, manutenção e limpeza do local, os moradores da COHAB se ocupavam com brigas, até o ponto de construírem uma cerca para dividir os terrenos. Insatisfeitos com a cerca, os moradores do Conjunto Paulo Freire acharam por bem presentear $^{5}$ os vizinhos, substituindo a cerca por um muro ${ }^{6}$.

A rivalidade entre $\mathrm{O}$ Conjunto Paulo Freire e o Conjunto da COHAB em alguns momentos parece estar menos nas relações entre os vizinhos, e mais nos ideais de base de cada qual dos projetos. Nos possibilita intuir tal possibilidade o fato de que entre os conjuntos Paulo Freire e o Unidos Venceremos a relação é de afinidade tamanha que chegam mesmo a fazer compras de materiais para construção juntos. Ambos têm bases autogestionárias. 
A zeladora/proprietária do conjunto Unidos Venceremos afirmou ter boas relações com os vizinhos do Paulo Freire, porém mencionou o medo de possíveis invasões dos moradores de habitações precárias ao redor. Preocupava-se ao ponto de esclarecer para várias pessoas do bairro que o conjunto não era uma posse ou invasão, e sim uma propriedade legal, adquirida junto a projetos. Inclusive afirmou que se os moradores das adjacências se unissem e se cadastrassem, também conseguiriam ser proprietários legais de um imóvel.

\section{REGIÃO MORAL}

Se ao abordar o conceito de demanda observa-se distinções nos discursos do Estado, da sociedade organizada e da assessoria técnica, no que diz respeito a hierarquia dos merecedores das políticas de habitação de interesse social parece haver critérios que se aproximam do consenso. Há elementos uníssonos entre os agentes do estado, os demandantes e as assessorias técnicas.

O ter família aparece como um critério decisivo do merecimento da política de habitação de interesse social, como um atestando objetivo de necessidade e, com parcimônia, de boa conduta. Tal observação se estrutura na idéia de que a família é um ser moral, que se diz, se pensa e se representa como um todo. E do todo para a parte, o indivíduo que se inscreve em projetos autogestionários deve ser trabalhador. Preserva-se nas políticas de habitação a oposição à vadiagem e enaltecimento da ordem ditada pelo Estado.

A política social elaborada pelo Estado trata-se, grosso modo, de uma engenharia em prol da manutenção de um sistema onde a família é a célula, para a qual cumpre a função de transmissão de valores essenciais da convivência civil, como a dignidade da pessoa, a confiança mútua, o bom uso da liberdade, o diálogo, a solidariedade, a obediência e respeito à autoridade.

A questão da ordem é central nos estudos de antropologia urbana da Escola de Chicago, sobretudo com base no conceito de "região moral" elaborado por Park ([1924] 1987). O autor observa que a proximidade e convívio urbano suscitam ordens. Essas ordens oprimem as paixões humanas em prol de uma civilidade.

Não é preciso entender-se pela expressão "região moral" um lugar ou uma sociedade que é necessariamente ou criminosa ou anormal, antes ela foi proposta para se aplicar às regiões onde prevaleça um código moral divergente, por uma região em que as pessoas que a habitam são dominadas, de uma maneira que as pessoas normalmente não o são, por um gosto, por uma paixão, ou por algum interesse que tem suas raízes diretamente na natureza original do individuo. Pode ser uma arte, como a musica, ou um esporte, como a corrida de cavalos. Tal região diferiria de outros grupos sociais pelo fato de seus interesses serem mais imediatos e mais fundamentais. Por essa razão, suas diferenças tendem a ser devidas mais a um isolamento intelectual (PARK, 1973, p. 66).

Park aponta a questão do controle social que figura na transição das instituições tradicionais (como igreja, escola e família) reprimindo o indivíduo, para a ordem legal, com base positiva. A região moral seria uma região onde os indivíduos expressariam suas paixões. Não trata-se necessariamente de uma região onde imperam os vícios, mas sim de uma 
região que libere as disposições naturais, tal como a arte, o esporte e a diversão.

Partindo do conceito de região moral, com vistas a contenção dos impulsos que não convém à ordem, há nos projetos autogestionários bastante preocupação com a criação de áreas de segregação que atendem gostos, interesses e temperamentos, como é o caso de uma quadra de esportes, um centro social ou um espaço de reuniões.

Em todos os conjuntos visitados havia o que trabalhamos como região moral. Como exemplo podemos citar que no conjunto Pirineus o terraço do prédio era utilizado para reuniões e festas.

No Colinas assistimos a uma palestra justamente no espaço para atividades diversas, a qual no período de obras servia de refeitório e depósito de alguns materiais. No Conjunto Vila Patrimonial uma mutirante apontou com gosto para um lugar privilegiado, bem embaixo de uma árvore exuberante, dizendo que ali seria construído um Centro Comunitário. No Paulo Freire havia um espaço com uma pequena copa onde se afixavam cartazes e os moradores se reuniam. Por sinal, este mesmo espaço fora oferecido em empréstimo aos moradores do conjunto da COHAB para se reunirem, se organizarem e tratarem de suas questões.

A questão moral atravessa os discursos de todos os agentes. A sociedade civil organizada, parte mais interessada nos projetos de habitação autogestionária, além de se ajustar a critérios morais torna-se zeladora e propagadora dos mesmos, em medida considerável. Mencionam reiteradamente que nos conjuntos habitacionais moram famílias, trabalhadores e não baderneiros, vândalos ou vagabundos. O alinhamento com os preceitos morais atinge um nível em que determinadas ações do Estado desfavoráveis aos mutirantes acabam sendo consideradas inaceitáveis, incoerentes.

\section{O TEMPO E O ESPAÇO}

Nas histórias de vida narradas pelas pessoas envolvidas nos projetos de habitação autogestionadas o tempo é um conceito que logo vem à baila. Quando perguntados sobre o tempo que cada projeto leva para se concretizar nenhuma resposta foi dada sem uma pequena pausa e um leve sorriso. Não se trata de um tema exatamente engraçado, mas de uma questão complexa.

Cada um dos projetos tem uma história própria, as quais alongariam demais esta etnografia se descritas minuciosamente. Entretanto, essas histórias podem ser contadas a partir de fatores comuns que informam o tempo mais reduzido ou mais longo de suas investidas.

As gestões políticas municipais, estaduais e federais influenciam cada fase dos projetos, desde a conquista do terreno, dos recursos e mesmo as regras que regulam a parte técnica das construções.

As eleições políticas e as nomeações de cargos públicos direta ou indiretamente relacionados com as políticas habitacionais compõem uma trama sofisticada que incide no tempo relativo de efetivação de um projeto.

Os discursos dos mutirantes, dos líderes de movimentos e dos profissionais de assossoria técnica são perspicaz no que diz respeito às transições políticas. Os sujeitos envolvidos no processo de produção da moradia autogestionada conseguem mencionar os mandatos e nomeações que impulsionaram mais 
projetos, ou os que emperraram as obras e projetos.

Um emblema da centralidade da questão política amalgamado pelas noções de tempo e espaço é uma placa na portaria do Edifício Pirineus, único projeto visitado na região central de São Paulo, com a seguinte inscrição: Governo do Estado de São Paulo, Conjunto Habitacional Pirineus $-1^{\text {a }}$ Vitória, Geraldo Alckmin Governador do Estado de São Paulo, Barjas Negri - Secretário de Estado da Habitação e presidente da CDHU, inaugurado em 04 de Setembro de 2003.

\section{É possível observar a questão} política nos discursos dos elementos envolvidos nos projetos de habitação autogestionária a partir de uma etnografia de como transcorre a vida das pessoas no Recanto das Emas, localidade adensada pela doação de lotes em Brasília. Borges (2004) trabalha o Tempo de Brasília. Em sua etnografia a autora sustenta que o voto trata-se de um processo ampliado e cotidiano de construção das relações de poder, de uma troca contínua, compulsória e parcelada. As obras públicas, argumenta Borges, devem ser algo sempre inacabado, eis que a dívida é necessária para a continuidade da relação.

\section{CONSIDERAÇÕES FINAIS}

Ao mencionar a ação do Estado vem à tona a instigante observação de Topalov (1996) de que os problemas urbanos nascem no início do século $X X$ por conta da necessidade de adequar as metrópoles e a sociedade ao mundo industrial, função esta levada a cabo por reformadores, urbanistas, filantropos e assistentes sociais. Topalov pontua que a sociedade e a cidade foram objetos da ação racional que prepararam terreno para o surgimento políticas sociais e urbanas modernas. E tais políticas, não raro, são incorporadas de forma naturalizada.

A partir da visita a projetos de habitação cooperativa em São Paulo, considerando ações, falas e discursos de agentes sociais organizados, assistência técnica e do Estado, conseguimos esboçar algumas considerações. Uma das primeiras é a reiteração da marca histórica de produção de habitações populares concentradas em zonas periféricas, decisão sustentada pelo Estado, tal qual esta fosse a única solução possível para as habitações de interesse social. Como exemplar tom de vitória está a exceção, o edifício Pirineus, fruto de uma luta de movimentos sociais na ocupação de imóveis ociosos na região central, associado a um projeto de reforma e reciclagem.

Apesar do adensamento habitacional nas regiões periféricas estimulado pelas políticas públicas, estas regiões permanecem com uma infra-estrutura bastante aquém da região central. Possivelmente em resposta à precária rede de transporte, serviços e equipamentos, oportunidades de trabalho e geração de renda, há um investimento dos moradores das áreas periféricas nos modelos de cooperação tradicionais, bem como a valorização da família, respeito à religião e referência ao Estado. Por parte do Estado há paliativos para essa carência, por exemplo, numa norma que prevê meio metro quadrado de área coberta para lazer por unidade construída nos projetos de habitações de interesse social.

Em relação à vizinhança os conjuntos cooperativados, grosso modo, instauram uma coesão interna que por um lado os fortalece politicamente e promove benefícios diretos para seus conjuntos habitacionais, e por outro lado os distinguem de projetos que não comunguem dos mesmos princípios. Um muro cabe como uma materialização de tal divisão. 
Por fim destacamos o quanto a habitação em si e a estrutura ao redor rumam ao sabor das tramas políticas, nas quais são elementares as noções de espaço e tempo, não raro a despeito da organização da sociedade.

\section{Bibliografia}

BORGES, Antonádia. Tempo de Brasília: etnografando lugares-eventos da política. Rio de Janeiro: Relume Dumará, 2004.

CANDIDO, ANTONIO. Os parceiros do Rio Bonito. Rio de Janeiro: José Olympio Editora (Coleção Documentos Brasileiros), 1964.

GOFFMAN, Erving. A representação do eu na vida cotidiana. Petrópolis: Vozes, 1975.

PARK, R. E. A cidade: sugestões para a investigação do comportamento social no meio urbano. IN: VELHO, O. G.(org.). O fenômeno urbano. Rio de Janeiro: Zahar, 1973.

PEIRANO, Mariza (org.). O Dito e o Feito. Ensaios de Antropologia dos Rituais. Rio de Janeiro: Relume Dumará/NuAP, 2001.
PERROT, Michelle. "A família triunfante" e "Funções da família". IN: PERROT, Michelle, História da Vida Privada - 4. São Paulo: Companhia das Letras, 1991.

TOPALOV, Christian. Da questão social aos problemas urbanos: os reformadores e a população das metrópoles em princípios do século $X X$. IN: RIBEIRO, Luiz Carlos de Queiroz; PECHMAN, Robert (org.). Cidade, povo e nação: gênese do urbanismo moderno. Rio de Janeiro: Civilização Brasileira, 1996.

1 Utilizo o que há em comum nos vocábulos dos dicionários Amora, Priberim, Houassis e Aurélio.

2 Tal observação não equivale a dizer que o Estado ignora as peculiaridades das demandas.

${ }^{3}$ Excluindo os trabalhadores que já atuam na construção civil.

${ }^{4}$ Companhia Metropolitana de Habitação.

5 Presentear foi exatamente o verbo utilizado pela moradora do conjunto Paulo Freire.

${ }^{6}$ O muro parece baixo visto do conjunto Paulo Freire, e alto visto do COHAB.

Contato:

Priscilla Oliveira Xavier

priscillaxavier@gmail.com

IPPUR/UFRJ

\section{Artigo recebido em Maio de 2011}

Artigo aprovado em Maio de 2011 